\title{
Miscellany
}

\section{New schizophrenia research centre}

HRH The Prince of Wales visited the proposed site of SANE's new \&6 million research centre into schizophrenia in Oxford recently. The new centre, to be named The Prince of Wales International Centre for Research into Schizophrenia and Depression, or POWIC for short, is planned to become a world centre for the study of serious mental illness.

\section{Leadership and innovation in mental health}

This project has been set up jointly by the NHS Training Division and the King's Fund. It is designed to meet the needs of managers and leaders in the mental health field, to encourage innovation, and to do so by providing short and practical programmes of direct relevance to managers and clinicians. Membership of the project will be by subscription and programmes will be subsidised from the NHS TD and the King's Fund. Further information: Huw Richards, Andy Kennedy or Silva Roberts, King's Fund College (telephone 0171 727 0581).

\section{First interactive electronic journal of poychiatry}

Psychiatry On-Line is available on the WorldWide-Web, part of the Internet via a Uniform Resource Labour Locator which is given below. Manuscripts submitted via emall or by disk are welcomed. http:// www.cityscape.co.uk/users/ad88/psych.htm. Correspondence should be addressed to $\mathrm{Dr}$ Ben Green, Priory Lodge, Ford Road, Upton, Wirral, Merseyside.

\section{Appointment}

Professor Hugh Freeman, Past Editor of The Brittsh Journal of Psychiatry, has been appointed Visiting Professor at the University of Bern. Switzerland.

\section{New publications}

The Law Commission Report No. 231 Mental Incapacity is available from HMSO, price £21.85. It is the outcome of a five year inquiry into the law affecting mentally incapacitated adults.

Victims of Care: a commentary on the care of the mentally ill in the community has been published by The Matthew Trust, PO Box 604, London SW6 3AG.

The Sainsbury Centre for Mental Health, 134-138 Borough High Street, London SE1 ILB (telephone 01714038790 ) has published a report Making Community Mental Health Teams Work.

Interface between Research and Practice has been published by the King's Fund. It is avallable from BEBC, PO Box 1496, Parkstone, Poole, Dorset BH12 3YD (telephone 0202 715555) and from the King's Fund Centre bookshop, price $\$ 8.00$.

St Andrew's Hospital, Northampton, has produced two information leaflets Alcohol Dependency Explained and Eating Disorders Explained which are available free by sending a stamped, addressed envelope to St Andrew's Hospital Alcohol Leaflet/Eating Leaflet, 52-54 Broadwick Street, London WIV IFF.

A self-help guide How to Cope with Loneliness is available from MIND Publications, 15-19 Broadway, London E15 4BQ. (Please include a 50p piece and a 29p SAE.)

\section{Mencap workshop training package}

Planning for the future: wills, trusts and residential provision for people who have profound and multiple disabilities is one of a series of workshop training packages in support of parents and carers developed from the work of the Mencap Profound Intellectual and Multiple Disabilities Section. It costs $\$ 42.50$ and further information is available from Mencap PIMD Section. Piper Hill School, 200 Yew Tree Lane, Northenden, Manchester M23 OFF (telephone 0161998 4161; fax 0161 $9456334)$. 